\title{
Rancang Bangun Mesin Pembuat Begel Berdiameter 6 mm dengan Sistem Pneumatik
}

\author{
Eni Safriana*, Rofarsyam, Ragil Tri Indrawati \\ Jurusan Teknik Mesin, Politeknik Negeri Semarang \\ Jl. Prof. H. Soedarto S.H., Tembalang, Semarang 50275, Telp. +62247473417 \\ *E-mail: s4friana@gmail.com
}

Diterima: 29-03-2021; Direvisi: 02-04-2021; Dipublikasi: 26-04-2021

\begin{abstract}
Abstrak
Seiring perkembangan pembuatan mesin begel tidak serta merta menghasilkan begel dengan sudut bending sesuai dengan SNI. Tujuan penelitian ini adalah untuk melakukan rancang bangun mesin begel secara otomatis dengan menggunakan sistem pneumatik yang mampu membuat begel berbahan BJTP 24 dengan hasil bending sudut sebesar $90^{\circ}$. Metode penelitian yang digunakan dalam penelitian ini dimulai melalui proses perancangan desain mesin begel dengan menggunakan software Solidwork, dilanjutkan dengan pembuatan prototipe mesin begel dengan sistem pneumatik yang memiliki dimensi $1000 \mathrm{~mm}$ x $875 \mathrm{~mm}$ x $1032 \mathrm{~mm}$ dengan penggerak motor DC 300 watt, dan melakukan perhitungan kapasitas mesin guna mengetahui kinerja mesin. Hasil menunjukkan bahwa mesin ini mampu membuat begel dengan ukuran $9 \times 9 \mathrm{~cm}$ dan sudut bending yang dihasilkan sebesar $90^{\circ}$ dengan toleransi $\pm 1^{\circ}$, rata-rata ketidakakuratan sudut terjadi pada titik bending C. Untuk menghasilkan satu buah begel waktu yang dibutuhkan mesin adalah 10 detik, sehingga dalam satu jam mesin mampu menghasilkan 360 buah begel. Hasil penelitian ini menunjukkan bahwa sudut bending yang dihasilkan memenuhi standar yang berlaku yaitu SNI.
\end{abstract}

Kata kunci: begel; bending; pneumatik; sudut begel

\begin{abstract}
Abstrak
The development of the manufacture of the begel machine did not automatically produce the begel with a bending angle in accordance with the SNI. The purpose of this research is to design and build a machine automatically using a pneumatic system that is able to make jars made from BJTP 24 with a bending angle of 90 . The research method used in this research begins through the process of designing a machine design using Solidwork software, intuitively making a prototype of a begging machine with a pneumatic system which has dimensions of $1000 \mathrm{~mm} x 875 \mathrm{~mm} x$ $1032 \mathrm{~mm}$ with a 300 watt DC motor drive, and calculates the engine capacity. to see engine performance. The results show that this machine is capable of making stirrups with a size of $9 \times 9 \mathrm{~cm}$ and the resulting bending angle of $90^{\circ}$ with a tolerance of $\pm 1^{\circ}$, the average angle inaccuracy occurs at the $C$ bending point. To produce one bag, the machine takes 10 seconds, so that in one hour the machine can produce 360 pieces. The results of this study indicate that the resulting bending angle meets the applicable standards, namely SNI.
\end{abstract}

Keywords: begel; bending; pneumatic;begel angle

\section{Pendahuluan}

Seiring pesatnya pembangunan fasilitas publik seperti gedung, hotel, supermarket, sarana prasarana transportasi, rumah ataupun bangunan lainnya membutuhkan besi beton untuk kontruksi bangunan nya, salah satu jenis dari penggunaan besi beton adalah untuk begel. Permintaan akan kebutuhan begel tidak pernah sepi seiring semakin banyaknya perumahan yang di bangun, industri rumahaan pembuat begel masih menggunakan cara manual dengan mengandalkan tenaga manusia dalam memproduksi begel. Penggunaan cara manual dalam pembuatan begel menyebabkan ukuran begel tidak seragam, karena pengaruh dari skill pekerja dan energi yang terbatas dengan tenaga manusia. Begel (sengkang) adalah tulangan yang digunakan untuk menahan tegangan geser dan torsi dalam suatu komponen struktur, terbuat dari batang tulangan, kawat baja atau jaring kawat baja las polos atau ulir, berbentuk kaki tunggal atau dibengkokkan dalam bentuk L, $\mathrm{U}$ atau persegi dan dipasang tegak lurus atau membentuk sudut, terhadap tulangan longitudinal, dipakai pada komponen struktur lentur balok [1]. Dalam peraturan tersebut dijelaskan bahwa 
begel (sengkang) dapat dibuat dengan dua jenis kait yaitu dengan bengkokan kait $90^{\circ}$ dan bengkokan kait $135^{\circ}$ Penggunaan jenis kait dapat dikombinasi antar keduanya.

Beberapa peneliti telah mengkaji terkait dengan pembuatan mesin begel. Pembuatan mesin begel telah mengalami peningkatan, terutama dari sisi tenaga penggerak. Ahsanul dkk [2] melakukan rancang bangun mesin pembuat begel mekanis berdiameter $5 \mathrm{~mm}$ yang mampu menghasilkan 720 buah begel per jam dengan menggunakan motor listrik. Ardian dkk [3] juga telah melakukan rancang bangun mesin begel, akan tetapi mesin ini menghasilkan begel dengan dimensi yang terkadang tidak sesuai standar, dan konstruksi mesin yang cukup rumit dan mahal. Penggunaan tenaga penggerak selain tenaga motor juga telah dilakukan oleh beberapa peneliti. Penelitian terkait dengan pembuatan mesin bending begel untuk besi polos $8 \mathrm{~mm}$ menggunakan kontrol semi otomatis mikrokontroler arduino dengan aktuator pembengkok menggunakan air pneumatic valve [4]. Rancang Bangun Alat Bending Sengkang pada kolom skala laboratorium juga telah dilakukan dengan hasil pengujian menggunakan alat bending sengkang rata-rata waktu yang diperoleh untuk membuat lima sengkang adalah 28 detik [5]. Ahmad Setiawan [6] membuat alat penekuk begel yang memiliki 2 roller yang berfungsi untuk membengkokan begel dimana roller tersebut di gerakan oleh poros handle, yang mendapatkan tekanan dari tangan dengan lama pengerjaannya 45 detik untuk menekuk 3 begel dengan hasil 232 begel dalam satu jam produksi. Shinde1 dkk [7] membuat alat bending sengkang yang mampu menghasilkan 180 buah begel per jam dengan system hidraulik. Pembuatan alat Penekuk Begel. Pada sturuktur beton dengan sistem pengerjaan cukup menjepitkan besi tulangan lalu memutarkan pedal penggerak juga telah dilakukan [8]. Anzip dkk [9] merancang mesin pembuat sengkang persegi dengan sistem hidrolik dengan daya motor listrik sebesar 2,17HP. Sumiati dkk [10] telah membuat mesin bending rotary baja untuk aplikasi stand pot bunga diameter 8 dan 10 inch memiliki dimensi ukuran $550 \mathrm{~mm} \times 550 \mathrm{~mm} \times 1000 \mathrm{~mm}$ dengan sumber tenaga penggerak motor listrik. Pembuatan alat bantu penekuk begel cincin segiempat yang memiliki 2 komponen penekuk yaitu poros penekuk dan roller penahan, yang berfungsi untuk membengkokkan begel dengan penggerak motor listrik menggunakan sistem micro controller untuk begel $\varnothing 8$ mm [11]. Kohar [12] membuat mesin digital untuk memproduksi begel yang terdiri dari pelurus menggunakan press bearing untuk meluruskan besi, pembengkok menggunakan servo yang diatur secara digital sehingga ukurannya dapat dibuat sesuai keinginan, pemotong menggunakan sistem pneumatic dengan bantuan hidrolis dari kompresor.

Melihat hasil penelitian yang telah dilakukan oleh beberapa peneliti, terlihat bahwa hasil rancang bangun mesin begel belum mampu menghasilkan sudut pembengkokan sesuai standar SNI yaitu sebesar $90^{\circ}$ dan $135^{\circ}$. Oleh karena itu, perlu inovasi dalam rancang bangun mesin begel guna memenuhi sudut penekukkan begel yang sesuai SNI. Tujuan penelitian ini adalah untuk melakukan rancang bangun mesin begel secara otomatis dengan menggunakan sistem pneumatik yang mampu membuat begel berbahan BJTP 24 dengan hasil bending sudut penekukan sebesar $90^{\circ}$.

\section{Material dan metodologi}

Tahap perancangan menurut Shigley digambarkan pada suatu diagramalir, dengan komponen: pengenalan kebutuhan (recognition of need), perumusan masalah (definition of problem, sintesis (synthesis), analisis dan optimasi (analysis and optimization, evaluasi (evaluation), penyajian (precentation) [13]. Metode penelitian yang digunakan dalam penelitian ini dimulai melalui proses perancangan desain mesin begel denganmenggambar mesin sesuai standar [14] dengan menggunakan software SolidWork, dilanjutkan dengan pembuatan prototype mesin begel dengan sistem pneumatik yang memiliki dimensi $1000 \mathrm{~mm}$ x $875 \mathrm{~mm}$ x $1032 \mathrm{~mm}$, dan melakukan perhitungan kapasitas mesin guna mengetahui kinerja mesin. Metode pelaksanaan dalam pembuatan mesin pembuat begel berdiameter $6 \mathrm{~mm}$ dengan sistem pneumatik tersaji pada Gambar 1. 
Eni Safriana dkk /Jurnal Rekayasa Mesin

p-ISSN: 1411-6863, e-ISSN: 2540-7678

Vol.16|No.1|69-75|April|2021

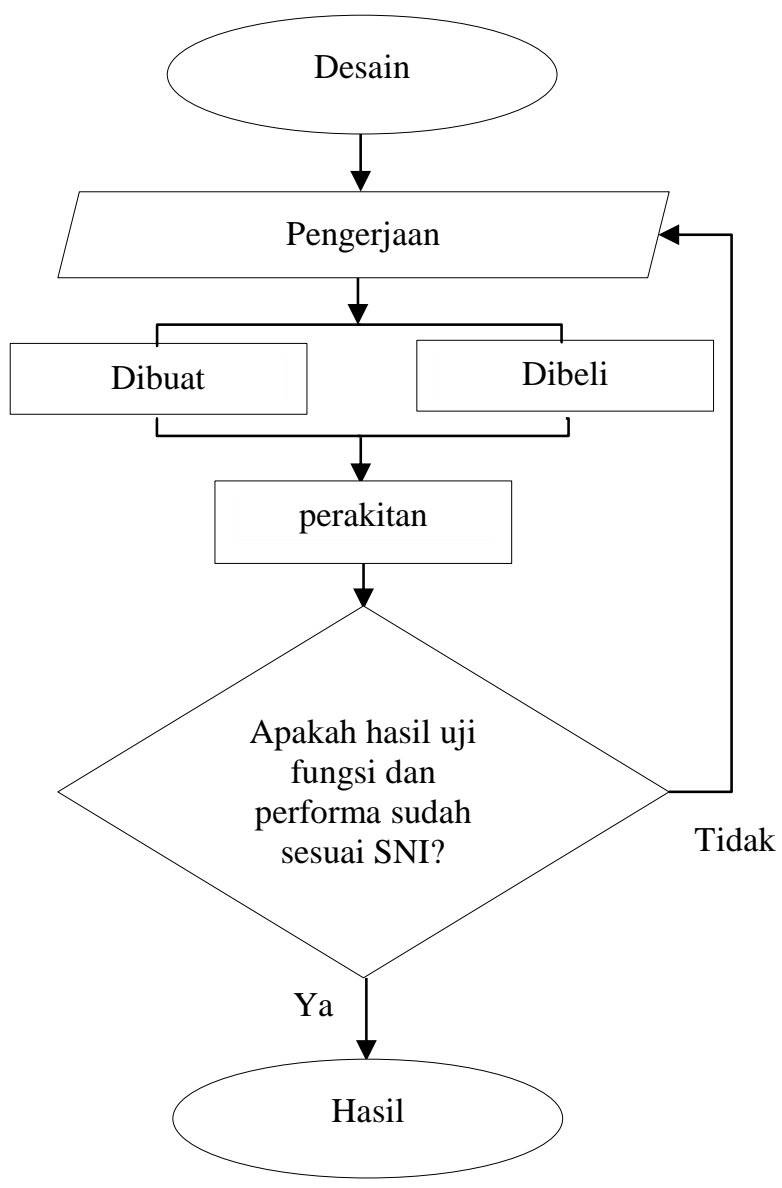

Gambar 1. Metode pembuatan mesin begel

Bahan yang akan digunakan pada rancang bangun mesin pembuat begel berdiameter $6 \mathrm{~mm}$ dengan sistem pneumatik untuk membuat begel yaitu baja tulangan beton BJTP 24. Menurut sifat mekanik baja tulangan beton BJTP 24 memiliki $r$ max $=380\left(\frac{\mathrm{N}}{\mathrm{mm}^{2}}\right)$ [15]. Komponen yang digunakan dalam pembuatan mesin begel berdiameter 6 $\mathrm{mm}$ dengan sistem pneumatik ini meliputi komponen-komponen standar dan komponen non standar yang dimodifikasi sesuai fungsi dan kebutuhan mesin. Serangkaian permesinan dibutuhkan untuk membuat komponen-komponen penyusun mesin pembuat begel otomatis dengan system pneumatic seperti proses bubut, frais, drill, gerinda, penyambungan las, dan lain-lain. Komponen-komponen standard yang digunakan diantaranya motor DC, silinder pneumatic, solenoid valve, bearing, mur dan baut, roda gigi. Komponen-komponen non standar yang digunakan untuk membuat mesin begel ini diantaranya rangka, rumah bearing, dudukan silinder, pisau pemotong. Pembuatan dan perakitan mesin begel berdiameter $6 \mathrm{~mm}$ dengan sistem pneumatic dilakukan di Laboratorium Teknik Mesin.

Untuk membuat satu buah begel terdapat lima bagian panjang yaitu L1,L2, L3, L4, dan L5 (Gambar 2). Mesin yang dirancang harus memiliki kinerja yang optimum. Waktu adalah salah satu parameter untuk mengetahui kinerja suatu mesin yang telah dirancang. Dalam perancangan mesin begel ini, waktu yang diperlukan untuk membuat satu buah begel tersaji pada persamaan 1, dimana waktu $t$ dalam detik, panjang $L$ dalam meter dan kecepatan $v$ dalam meter/detik

$$
t=L / v \rightarrow t_{\text {penarikan }}=[t 1+t 2+t 3+t 4+t 5]=[(L 1 / v)+(L 2 / v)+(L 3 / v)+(L 4 / v)+(L 5 / v)] \cdots
$$


Eni Safriana dkk /Jurnal Rekayasa Mesin

p-ISSN: 1411-6863, e-ISSN: 2540-7678

Vol.16|No.1|69-75|April|2021

12

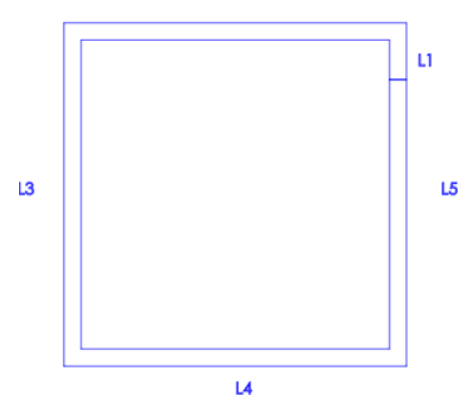

Gambar 2. Dimensi begel

\section{Hasil dan pembahasan}

Prinsip kerja mesin pembuat begel ini yaitu dengan cara lonjoran baja berpenampang lingkaran dengan diameter 6 mm sebagai material dilakukan penarikan, penekukan, dan pemotongan. Mesin pembuat begel pada Gambar 3, terdapat komponen-komponen yang terdiri dari 15 macam. Material dimasukkan ke roller pelurus kearah roller penggerak, hingga penekuk. Pada saat mesin beroperasi material tersebut akan ditarik, ditekuk, dan dipotong. Mesin pembuat begel ini terdiri atas tiga bagian utama yaitu penarik, penekuk, dan pemotong. Penekuk pada mesin ini berupa silinder pneumatik yang ujungnya diberi pembending berfungsi sebagai penekuk material hingga membentuk sudut $90^{\circ}$ sebagai sudut sisi dari begel. Penarik pada mesin ini berupa roller yang berfungsimenggerakkan material kearah penekuk untuk dilakukan pengerjaan berikutnya, pemotongan ataupun penekukan. Pemotong pada mesin ini berupa pisau beton berbentuk persegi yang dihubungkan dengan sebuah lengan yang akan dikaitkan dengan silinder pneumatik yang berfungsi memotong material ketika telah tiba di akhir langkah pembentukan satu buah begel.

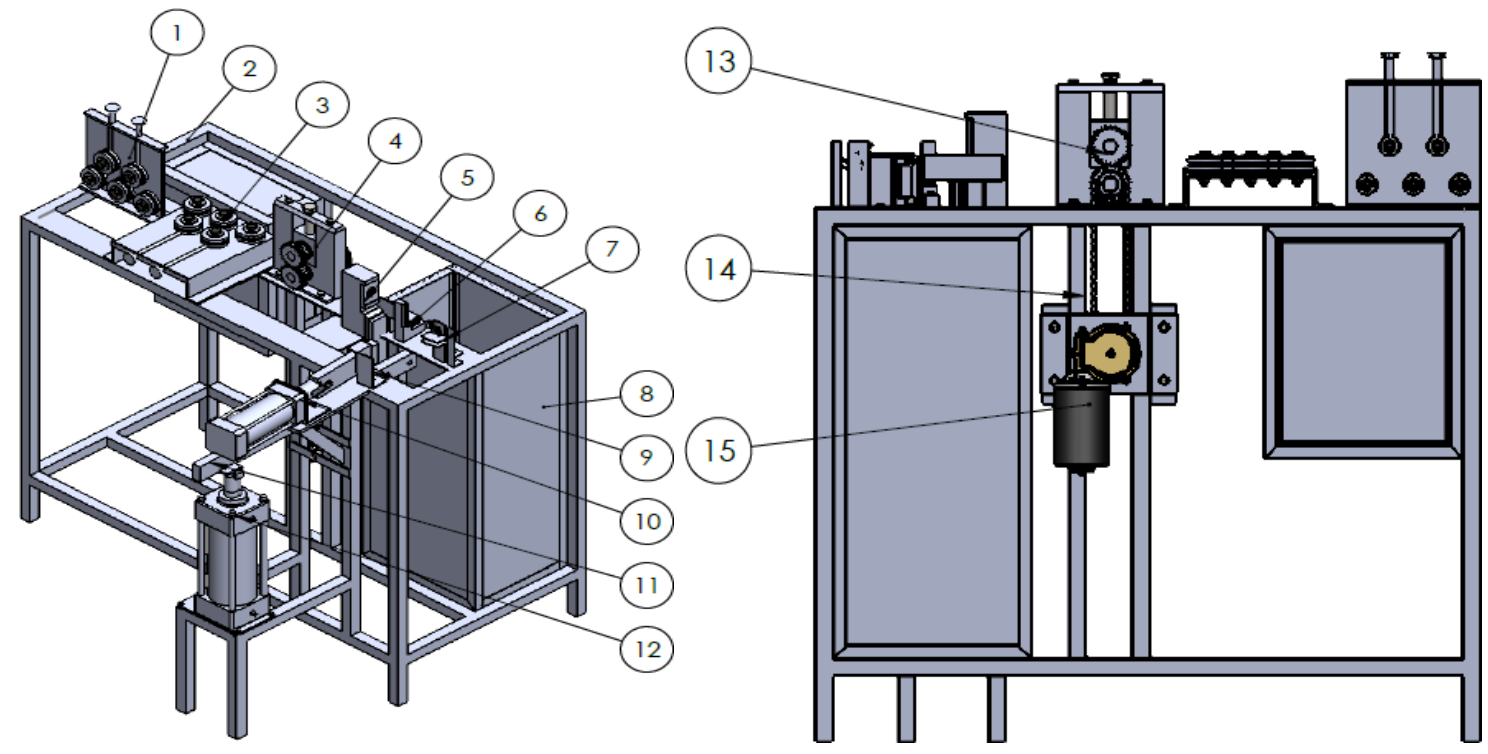

\begin{tabular}{ll}
\hline \multicolumn{2}{l}{ Keterangan: } \\
1 & Pelurus I \\
2 & Rangka \\
3 & Pelurus II \\
4 & Roller penarik \\
5 & Penepat Besi Tulangan \\
6 & Fixture Penekuk \\
7 & Limit Switch \\
8 & Box Penampung \\
\hline
\end{tabular}

$9 \quad$ Penepat Bending

10 Pneumatik Bending

11 Tuas Potong

12 Pneumatik Potong

13 Roda Gigi

14 Sproket

15 Motor DC

Gambar 3. Mesin begel tampak isometris dan tampak depan 
Pengujian dilakukan untuk mengetahui nilai sudut yang terbentuk berdasarkan parameter yang diberikan juga kapasitas mesin. Untuk membentuk satu buah begel, mesin ini membutuhkan waktu 10 detik, sehingga dalam 1 jam, mesin ini mampu menghasilkan 360 buah. Output nilai sudut yang dihasilkan adalah $90^{\circ}$ disemua titik bending dengan toleransi $\pm 1^{\circ}$ sehingga sudut antara pembending dan material sebesar $95^{\circ}$. Titik bending untuk satu buah begel terdiri dari 5 titik (A, B, C, D dan E ) seperti terlihat pada Gambar 4. Berdasarkan Tabel 1 kegagalan hasil dalam mencapai sudut yang dikehendaki rata-rata terjadi pada titik bending $\mathrm{C}$, hal ini dapat dikarenakan tekanan yang kurang dari kebutuhan yaitu 8 bar.

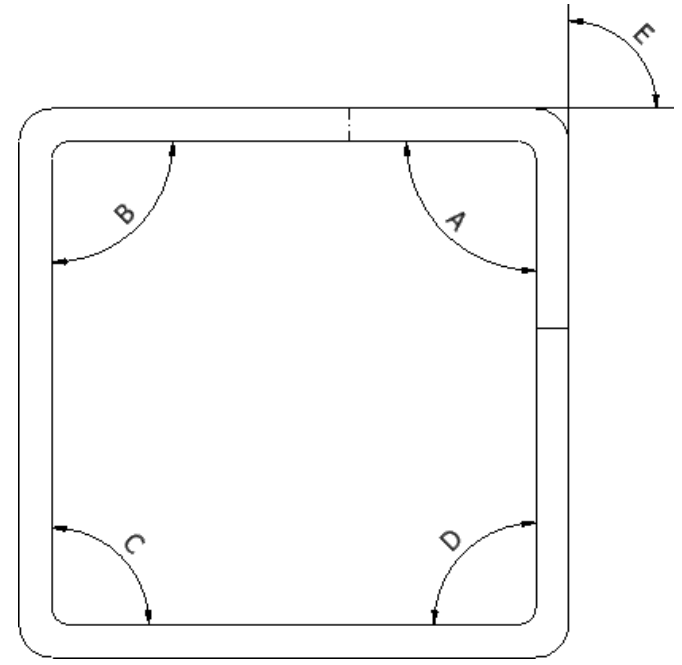

Gambar 4. Titik bending pada begel

Tabel 1. Hasil pengujian sudut begel dengan kemiringan antara pembendingan dengan material sebesar $95^{\circ}$

\begin{tabular}{cccccc}
\hline \multirow{2}{*}{ Pengujian ke - } & \multicolumn{5}{c}{ Sudut yang terbentuk di tiap titik bending } \\
\cline { 2 - 5 } & $\mathrm{A}$ & $\mathrm{B}$ & $\mathrm{C}$ & $\mathrm{D}$ & $\mathrm{E}$ \\
\hline 1 & $90^{\circ}$ & $92^{\circ}$ & $95^{\circ}$ & $89^{\circ}$ & $90^{\circ}$ \\
2 & $90^{\circ}$ & $90^{\circ}$ & $92^{\circ}$ & $90^{\circ}$ & $90^{\circ}$ \\
3 & $91^{\circ}$ & $90^{\circ}$ & $95^{\circ}$ & $89^{\circ}$ & $90^{\circ}$ \\
4 & $90^{\circ}$ & $90^{\circ}$ & $95^{\circ}$ & $95^{\circ}$ & $90^{\circ}$ \\
5 & $90^{\circ}$ & $90^{\circ}$ & $90^{\circ}$ & $90^{\circ}$ & $95^{\circ}$ \\
6 & $90^{\circ}$ & $90^{\circ}$ & $93^{\circ}$ & $90^{\circ}$ & $91^{\circ}$ \\
7 & $90^{\circ}$ & $90^{\circ}$ & $94^{\circ}$ & $90^{\circ}$ & $90^{\circ}$ \\
8 & $90^{\circ}$ & $90^{\circ}$ & $93^{\circ}$ & $95^{\circ}$ & $90^{\circ}$ \\
9 & $90^{\circ}$ & $90^{\circ}$ & $92^{\circ}$ & $90^{\circ}$ & $90^{\circ}$ \\
10 & $90^{\circ}$ & $90^{\circ}$ & $92^{\circ}$ & $95^{\circ}$ & $90^{\circ}$
\end{tabular}

Pengujian dilakukan dengan variabel sudut sebesar $95^{\circ}$, terhadap titik penekukan A, B, C, D dan E. Pengujian dengan sudut antara pembending dan material sebesar $95^{\circ}$ menghasilkan begel dengan sudut $90^{\circ}$ sesuai standar dengan toleransi $\pm 1^{\circ}$. Hasil pengujian begel seperti terlihat pada Gambar 5 . 


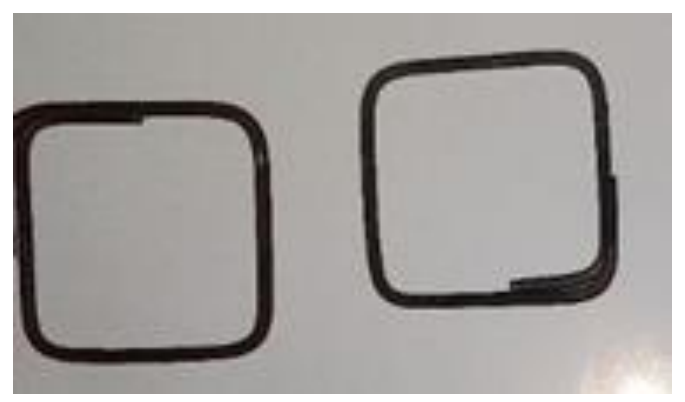

(a)

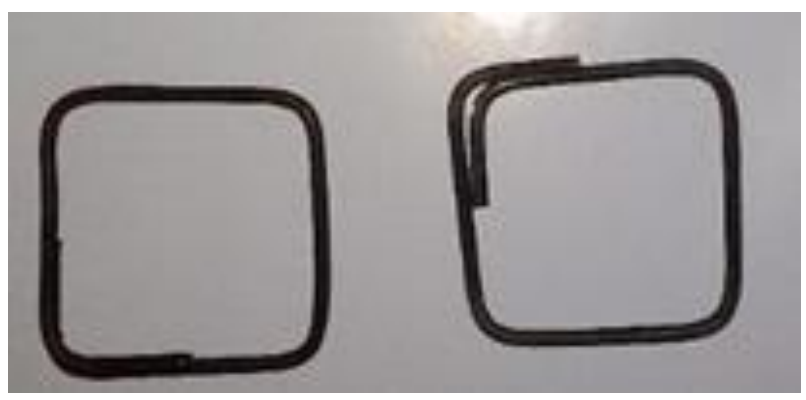

(b)

Gambar 5. Hasil Pengujian begel (a) begel sesuai standar dan (b) begel tidak sesuai standar

\section{Kesimpulan}

Rancang bangun mesin pembuat begel dengan diameter $6 \mathrm{~mm}$ menunjukkan kinerja yang optimum. Hal ini terlihat pada hasil pengujian yang dilakukan terhadap begel yang dibuat memiliki ukuran 9x9 $\mathrm{cm}$ dan sudut yang dihasilkan sebesar $90^{\circ}$ dengan toleransi $\pm 1^{\circ}$, rata - rata ketidakakuratan sudut terjadi pada titik bending C. Untuk menghasilkan satu buah begel waktu yang dibutuhkan mesin adalah 10 detik, sehingga dalam satu jam mesin mampu menghasilkan 360 buah begel.

\section{Daftar Pustaka}

[1] Badan Standardisasi Nasional. SNI03-2847-2002. Tata Cara Perhitungan Struktur Beton Untuk Bangunan Gedung. Bandung: Departemen Pekerjaan Umum, Yayasan Lembaga Penyelidikan Masalah Bangunan; 2002

[2] Ahsanul, K., dkk. Rancang Bangun Mesin Pembuat Sengkang Mekanis Diameter 5 MM Dengan Kapasitas 720 Buah Per Jam. Semarang: Politeknik Negeri Semarang. 2018.

[3] Adian, W., dkk. Rancang Bangun Mesin Bending Otomatis Untuk Begel Diameter 8 MM. Palembang : Politeknik Negeri Sriwijaya. 2016.

[4] Miftahul, H., Priyagung, H., Unung, L., Perancangan Mesin Bending Begel (Ring) Dengan System Pneumatic. Jurnal Teknik Mesin, Jurnal Sains dan Teknologi Mesin Unisma, 2021; 16(3).

[5] Lovely, S., Fendra, S., Rancang Bangun Alat Bending Sengkang pada Kolom Skala Laboratorium. Jurnal Teknika, 2014; 21(3).

[6] Ahmad, S., Rancang Bangun Alat Bantu Penekuk Begel Cincin Segiempat Untuk 5 Konstruksi Beton. Palembang: Politeknik Negeri Sriwijaya. 2014.

[7] Vilas, S., Darshan, A., Suraj, J., Afsar, A., Sandip, G., Design and Fabrication of Hydraulic Stirrups Making Machine. International Journal of Innovative Research in Science, Engineering and Technology (An ISO 3297: 2007 Certified Organization). May 2016; 5(5).

[8] Rahman, A.A., Alat penekuk sengkang (begel) pada sturuktur beton. Jurnal teknologi pertanian gorontalo. 2017;1(2).

[9] Arino, A., Subowo, Bambang, S., Suhariyanto, W., Pandu, K., Annisa. L., Rancang Bangun Mesin Pembuat Sengkang Persegi Dengan Sistem Hidrolik. Seminar Nasional Inovasi dan Aplikasi Teknologi di Industri 2018 ISSN 2085-4218, Tema A - Penelitian ITN Malang, 3 Pebruari 2018

[10] Ruzita, S., Genta, R., Rakiman, Fardinal, Pembuatan Dan Pengujian Mesin Bending Rotary Baja Untuk Aplikasi Stand Pot Bunga Diame Ter 8 Dan 10 Inch. Jurnal Teknik Mesin (JTM). 2020; 13(1) 
[11] Kurnia, M., Rancang Bangun Mesin Bending Otomatis Untuk Begel Diameter 8 mm. Palembang: Politeknik Negeri Sriwijaya. 2016

[12] Abdul, K., Mesin Digital Untuk Memproduksi Begel. Direktorat Paten, DTLST, dan RD , S00202008689, 2021

[13] Richard, G., Budynas, N., Keith. J., Shigley’s Mechanical Engineering Design. Ninth Edition. New York: Mc. Graw Hill; 2011.

[13] Sato, G.T., Sugiarto, N.H., Menggambar Mesin Menurut Standar ISO. PT. Pradnya: Jakarta; 2002

[15] Badan Standardisasi Nasional. SNI07-2052-2002. Baja Tulangan Beton. Bandung: Departemen Pekerjaan Umum, Yayasan Lembaga Penyelidikan Masalah Bangunan; 2002 